\title{
Research on Innovation Behavior and Performance of New Generation Entrepreneur Based on Grounded Theory
}

\author{
Hongjun Guan ${ }^{1}\left(\mathbb{D}\right.$, Zhen Zhang ${ }^{1}$, Aiwu Zhao ${ }^{1,2, *}$, Jinyuan Jia ${ }^{2}$ and Shuang Guan ${ }^{3}$ \\ 1 School of Management Science and Engineering, Shandong University of Finance and Economics, Jinan \\ 250014, China; jjxyghj@sdufe.edu.cn (H.G.); zhangzhen@mail.sdufe.edu.cn (Z.Z.) \\ 2 School of Management, Jiangsu University, Zhenjiang 212013, China; jsdxjjy@126.com \\ 3 Courant Institute of Mathematical Sciences, New York University, New York, NY 10012, USA; \\ sg5896@nyu.edu \\ * Correspondence: aiwuzh@ujs.edu.cn
}

Received: 10 April 2019; Accepted: 17 May 2019; Published: 21 May 2019

\begin{abstract}
In China, new generation entrepreneurs are gradually becoming the main force of intergenerational inheritance. New generation entrepreneurs have different educational background, growth experience and personality characteristics from the old generation entrepreneurs. They are endowed with the historical mission of an innovative generation. Therefore, it is of great significance to reveal the key factors influencing their innovative behavior and find out how to inspire their innovative behavior. Based on grounded theory and in-depth interviews, this study used NVivo 11 to deal with the recording materials. After a series of steps including open coding, spindle coding, selective coding and theoretical saturation test, it constructed a theoretical model of innovative behavior and innovative performance for new generation entrepreneurs. The purpose of this study was to improve the theory of entrepreneur innovation behavior and provide guidance for government to cultivate innovative spirit and innovative ability of new generation entrepreneurs. The research showed that: (1) New generation entrepreneurs' personal traits and educational background affect their perceptions of innovation. (2) Risk awareness, understanding of innovation content and social capital would influence innovation behaviors. (3) Innovation behaviors further lead to changes in organization performance. Therefore, government should provide more opportunities for new generation entrepreneurs to widen their knowledge, social resources and innovation environment.
\end{abstract}

Keywords: new generation entrepreneurs; innovation behaviors; depth interview; grounded theory

\section{Introduction}

With the changes of time, the older generation entrepreneurs gradually leave the stage, and the new generation entrepreneurs gradually rise to become the main force of enterprises [1]. There are two reasons for this. On the one hand, family businesses in China are in a period of intensive inheritance from the old to the new. Family business refers to any type of business operation in which a group of relatives have controlling rights over the company. In many cases, family businesses are passed from one generation to the next [2]. On the other hand, the new generation entrepreneurs themselves have a strong desire to found organizations [3]. According to a survey conducted by China Family Business Review on new generation entrepreneurs and organizations, and a white paper published in 2017 on the second Chinese new generation entrepreneurs' organizations and the current situation of Chinese new generation entrepreneurs show that nearly $90 \%$ of the new generation entrepreneurs do not exclude possibility of taking over family businesses. Fifty-seven percent of new generation entrepreneurs hope to be called "entrepreneurs" or "second generation" and have great enthusiasm 
for entrepreneurship [4]. At the Forum of New Generation Entrepreneurs, Chen and Chen (2013) [5] regarded the new generation entrepreneurs as the most dynamic and innovative group in this era and the essential group of new economic development. Through the analysis of many existing studies, it is found that scholars mostly take the new generation entrepreneurs from Zhejiang and Jiangsu as the research objects to explore the growth and characteristics of the new generation entrepreneurs. For example, some scholars have studied the role of schools, enterprises and families in the formation of entrepreneurship among adolescents, and explored how to promote the formation of a new generation of entrepreneurship among adolescents [6,7]. Some scholars have studied how to guide the new generation private entrepreneurs to generate innovative will and put it into practice $[8,9]$. In addition, considering the characteristics of new generation entrepreneurs, Fan and $\mathrm{Lu}$ (2019) [10] put forward some suggestions to promote the healthy growth of private entrepreneurs from the perspectives of capacity-building mechanism, political participation mechanism and social participation mechanism. However, research on influencing factors of the new generation entrepreneurs' innovation behaviors and innovation performances is seldom performed [8]. For example, Chen (2007) [11] defined the identities of the new generation entrepreneurs by sorting out the growth processes of the old generation entrepreneurs and positioned the new generation entrepreneurs as the main force to carry the national economic revitalization in the development of socialist market economy. Jiang and Cao (2016) [12] studied the value orientations and political guidance of the new generation entrepreneurs. They found that the value orientations of the new generation entrepreneurs were mostly positive and healthy, but there were still problems in political cognition, political participation and their own development. Entrepreneurs are the decision makers of enterprise. The cultivation mechanism of the new generation entrepreneurs should be formulated by means of government guidance, enterprise leadership and social participation. That is to say, we should take thematic activities as the carrier and focus on promoting the development concept; and take "one-to-one" contact as a platform, and strive to broaden communication channels. With multi-directional training as the starting point, we should strive to improve the overall quality. With excellent service as the main line, efforts should be made to optimize the development environment [13].

The rest of this paper is organized as follows: Section 2 reviews the relevant research on entrepreneur innovation behavior and the impact of entrepreneur innovation on organizational performance. Section 3 introduces the research methods and process: how to encode interview data to three levels based on grounded theory, and finally get the research model. Section 4 analyzes the influencing factors of innovative behavior of new generation entrepreneurs from macro and micro perspectives. Section 5 discusses the research results and draws conclusions and prospects.

\section{Review}

\subsection{The Definition of New Generation Entrepreneurs}

The new generation entrepreneurs are a group of young entrepreneurs with high educational background, high quality, adventurous spirit and pursuit of personality [14]. They are quite different from older generation entrepreneurs. The new generation entrepreneurs was born in the Internet era and grew up in the stable era of rapid economic development. They are very adventurous, anti-traditional, break the convention and Internet thinking, and generally have a higher level of education. They are familiar with the development characteristics of the new economic era, have received higher education and have an international perspective. However, the older generation entrepreneurs are more focused on being the best in a special industry, producing competitive products and building a solid foundation for the enterprise [15]. "New-generation entrepreneurs" is a new concept and scholars neither domestic nor abroad have a clear definition. By combing the research on new-generation entrepreneurs [16], we found several definitions of new-generation entrepreneurs: (1) The famous American writer Stuart (2004) defined new generation entrepreneurs as the creators of wealth and the reshapers of business in the new era. They have totally different views, especially in 
business. They are the darlings of the new era and the combination of entrepreneurs and managers [17]. (2) Li et al. (2009) [18] defined the new generation entrepreneurs as: the new generation entrepreneurs just caught up with the wave of China's excellent national policy of reform and opening up and achieved rapid growths in the vigorous development of market economy. They have some characteristics, such as young, highly educated, highly skilled, high starting point of management and strong innovation awareness. They have their own enterprises and they have won market recognition by virtue of core technologies, products or services. (3) The division of entrepreneurs and their functions is mainly accomplished by economists. At the beginning, researchers believed that entrepreneurship would run through the whole business process, and the profits the enterprise earned were a kind of return. Because they cannot completely distinguish between management and entrepreneur functions, and between small and large enterprises, it is generally believed that entrepreneur functions are to establish and manage small enterprises [19]. Afterwards, Schumpeter and later researchers began to turn to the innovative role of entrepreneurs, that is, to eliminate existing methods and products through continuous innovative activities. Western scholars' understanding of entrepreneurs' functions has undergone a gradual deepening process [20]. As we all know, the emergence of entrepreneurs is accompanied by the development of productivity, the expansion of enterprise scale and the emergence of joint-stock companies. Therefore, the functions of entrepreneurs will inevitably show different characteristics with the changes of the times and the environment. Researchers from different countries have different criteria for the division of entrepreneurs. $\mathrm{Gu}$ (2007) divided Chinese entrepreneurs into four generations by studying the growth of Chinese local entrepreneurs and the characteristics of the times of Chinese local entrepreneurs: from the reform and opening-up in 1978 to Deng Xiaoping's Southern Tour Speech in 1992 is the first generation entrepreneurs; from Deng Xiaoping's Southern Tour Speech in 1992 to the rise of the Internet in 2000 is the second generation entrepreneurs; from the rise of the Internet in 2000 to its maturity is the third generation entrepreneurs; and the fourth generation entrepreneurs are the object of our study: the new generation entrepreneurs [21].

Generally speaking, new generation entrepreneurs refer to a group of young entrepreneurs who were born in the Internet age and grew up in the stable era rapid economic development. Most of them are young entrepreneurs who have started their own businesses or inherited the first generation entrepreneurships. They are highly adventurous, anti-traditional, unconventional, Internet-minded and generally highly educated, and advocate freedom and pluralistic values. They are familiar with the development characteristics of the new economic era and have international perspectives.

\subsection{Relevant Research on Innovation Behaviors of New Generation Entrepreneurs}

The earliest research on innovation in foreign academic circles originated from Schumpeter, the father of innovation theory. Overall, foreign scholars focus on the impact of enterprise's own factors (such as organizational learning ability, absorptive capacity, etc.) on innovation behavior and performance, and then discuss enterprise innovation behavior from the perspective of external space (such as industrial clusters, social networks, etc.). Domestic academic research on enterprise innovation behavior can be roughly divided into three categories: research on the influencing factors and mechanism of various types of enterprise innovation behavior, research on enterprise innovation behavior using innovative theoretical tools, and research on the performance of innovation behavior and its influencing factors [22]. With the development of the times, the new-generation entrepreneurs play an increasingly important role in the process of economic development. More and more scholars begin to pay attention to the new-generation entrepreneurs, and it becomes very meaningful to explore the influencing factors of their innovative behavior and performance. Scholars have explored the current situations and characteristics of new generation entrepreneurs and analyzed their growth laws, which is conducive for further study. The research on the innovation behaviors of new generation entrepreneurs is still in the exploratory stage [23]. In the existing research, most scholars mainly focus on the following aspects: The first focus is the current situations and growth of the new generation entrepreneurs. Wang (2018) [24], starting from the characteristics of the new generation private 
entrepreneurs, explored the problems faced by the new generation entrepreneurs in their growths and put forward a plan to promote the healthy growth of the new generation private entrepreneurs. The second is the obstacles in innovation behaviors of the new generation entrepreneurs. He et al. (2009) [25], starting from the innovation behaviors of private entrepreneurs, studied the obstacles of innovation behaviors of private entrepreneurs in China. Luan et al. (2016) [26] analyzed the basic situation of the new generation entrepreneurs and pointed out some difficulties faced by innovation entrepreneurship: lack of responsibility, low willingness of business entities, and lack of innovation experience and ideas. The third is the influence of innovation will and political guidance of new generation entrepreneurs. Gui et al. (2018) [27] studied the influencing factors of the innovation wills of the new generation private entrepreneurs.

By sorting out the relevant studies on entrepreneurs' innovation, the connotation of the innovation wills of the new generation was defined and a model of innovation will of the new generation private entrepreneurs was constructed based on the theory of planned behaviors [28]. From three aspects of behaviors attitude, subjective norms and perceived behaviors, this study comprehensively analyzed the influencing factors of innovative willingness of the new generation private entrepreneurs. Lal and Ronald W (2005) [29] studied the value orientation and political guidance of the new generation entrepreneurs. They found that different political guidance influenced the characteristics of new generation entrepreneurs and further changed their value orientations. The fourth is the impact of enterprise innovation on employment. Aldieri and Vinci (2018) [30] found that strong innovative actions can create more jobs to achieve the overall sustainable development of enterprises. Piva and Vivarelli (2018) [31] found that there is a positive effect of innovation on employment, which is more significant when product innovation is adopted as proxies of technological change. The fifth is the influencing factors of innovative behavior of new generation entrepreneurs. Kanter (1988) [32] shows that whether organizational culture is traditional-oriented or change-oriented, whether it is proud or inferior, and whether it can give employees a sense of security and values will affect their innovative behavior. Other studies have shown that support from leadership and organizational climate promotes innovative behavior [33-35].

\subsection{Relevant Research on the Impact of Entrepreneur's Innovation Behaviors on Organization Performance}

Organization performance cannot be separated from innovation behaviors, especially for entrepreneurs. Scholars define organization performance mainly in two categories [36]. One is guided by the innovation process; for example, Christensen believed that innovation performance is the result of the transformation of organizational creativity and innovation technology [37]. Another on is guided by the innovation results; for example, Prajogo and Hamed (2006) [38] believed that organization performance is one of the indicators to measure corporate profits, which can be achieved through products and services. By reviewing domestic and international literature, it was found that scholars hold different views on the impact of innovation behaviors on innovation performance. For example, Xiao and Chen (2006) [39], by studying innovation behaviors of entrepreneur management system, found that entrepreneurs' innovation of personnel management system, salary system and performance evaluation system effectively improved the growth performance of enterprises. Miotti and Schachwald (2003) [40] found that entrepreneurs' cooperative innovation with their stakeholders has a significant impact on organization performance. Shanker and Roy found that innovative work behavior plays a mediating role in the relationship between organizational climate for innovation and organizational performance [35]. Hogan and Coote (2014) [41] presented a key result on how layers of organizational culture, particularly innovative behaviors, partially mediate the effects of values that support innovation on measures of firm performance. Audretsch et al.(2014) [42] thought that innovation behaviors are the decisive factor of enterprise growth, especially innovation strategy and behavior determine the future growth potential and survival prospects of enterprise, and analyzed four main types of enterprise growth: organizational growth; creation of new enterprises; mergers and 
acquisitions of existing enterprises and transfer and diffusion of product or process-based innovation; and promote the growth of enterprises.

Generally speaking, as successors of China's economic development in the new era, the new generation entrepreneurs have become the mainstay of China's economic development. There are relatively few studies domestically or internationally. The existing studies mainly focus on the characteristics of the new generation entrepreneur and concern about dilemma in their growth process and the problems that may arise in the special node of the replacement of new and old entrepreneurs. Few studies involve the innovation behaviors of the new generation entrepreneurs and its influencing factors.

\section{Research Design and Method}

\subsection{Research Methods}

Grounded theory, proposed by Anselm Strauss and Barney Glaser of Columbia University in 1967 , is devoted to the interpretation and understanding of social phenomena, and advocates to extract concepts from daily life experience and social phenomena and construct theories. This theory is an inductive bottom-up research process, which starts from real life and collects data with research questions. Through three main coding processes of open coding, spindle coding and selective coding, the concepts and categories are summarized and refined from the original data. The process is to compare, summarize and classify the data and theories continuously, and establish the connection until a new theory reflecting the essence and significance of the phenomenon is constructed. The research process of grounded theory is shown in Figure 1. The grounded theory research method remedies the weakness of qualitative research that only emphasizes experience imparting and skill training, and provides a set of clear and systematic strategies to help researchers think, analyze, collate data, excavate and establish theory. Such kind of qualitative research is different from quantitative method. Quantitative research methods require theoretical hypotheses and inevitably depend on researchers' subjective judgment. Grounded theory can avoid this problem, because the theory does not need transcendental conclusions and hypotheses; data collection and data analysis are carried out at the same time. It is rooted in the coding and generic nature of the original data, rather than the assumption of the logical deduction that the researchers envisioned [43].

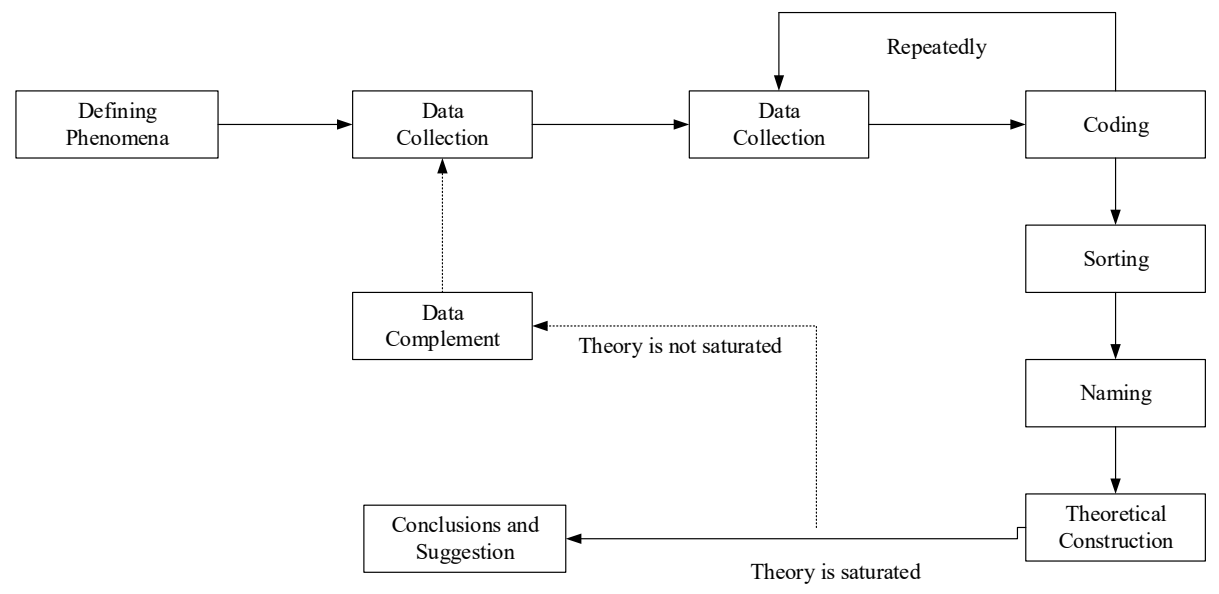

Figure 1. Flow chart of grounded theory.

This study mainly used NVivo for text analysis. NVivo is a powerful qualitative analysis software, which can effectively analyze a variety of different data, such as a large number of verbatim texts, image graphics, sound and video data. It provides many convenient tools to help us deal with complex materials. NVivo brings qualitative analysis and observation to a whole new level through a powerful intelligent application. Traditional grounded theory mostly uses manual copy and paste data for 
coding [44]. However, using NVivo to import data directly can quickly return to the original data and reduce coding omissions caused by copy and paste.

\subsection{Sample Selection and Data Collection}

By means of semi-structured interviews and text analysis, this study tried to find the key factors and variables in the innovation processes of the new generation entrepreneurs. Because grounded theory regards all aspects as sample data, we wanted to collect as detailed as possible data. Those details may include literature, oral materials and views, experience and historical records of respondents.

Firstly, to ensure the comprehensiveness and vividness of the information, we conducted two interviews. During the first interview, we constantly analyzed and compared the respondents' answers and collected data, and added new questions to the interview outline to form the second-round interview's outline. Then, a second interview was conducted until no new problems were found. Because qualitative research requires respondents to have a certain understanding on the issues studied, we conducted two in-depth interviews with 24 young entrepreneurs in Zhenjiang and Nanjing through the Zhenjiang Youth Federation. In the following interview processes, the collected data were constantly analyzed and compared, while new questions were added in time to form the second-round interview's outline. After a certain number of interviews, the interview data were collated and analyzed until no new problem arose.

Secondly, to ensure the typicality and representativeness of the data, this study took the entrepreneur innovation events found on the Internet as the research objects and collected in-depth reports from the network, newspapers and periodicals as well as forum posts and comments. Then, 32 typical case texts were formed after classifying, collating and synthesizing the interview outline.

Finally, based on semi-structured interviews and text analysis, two-thirds of the interviews were randomly selected for coding analysis and model construction, while the other one-third of the interviews were left for theoretical saturation test.

\subsection{Research Process}

\subsubsection{Open Coding}

Open Coding is an operational process that "crushes" and "breaks up" collected data, assigns conceptual labels, and then combines them in a new way to define concepts and discover categories. Specific steps are as follows: (1) labeling data, extracting corresponding concepts and defining phenomena; (2) deep analysis of concepts and mining more general categories; (3) giving exact names to categories; and (4) discovering and summarizing the nature and dimension of categories [45].

In the process of open coding, to avoid personal bias and existing "stereotypes" of thinking and research circles, the authors invited two other graduate students of management to compile the interview data sentence by sentence with the authors. When there were differences, they discussed further until they reached a consensus, ensuring the objectivity of the open coding. At the same time, considering that the innovations of the new generation entrepreneurs was mainly studied, after reviewing and analyzing the written materials, we deleted the unrelated content, divided it into several key events according to the topic of the interview and coded the 16 sampled interview records. Through the open coding of 16 interview materials, 38 free nodes were abstracted from the data and 1248 total reference points. To save space, Table 1 shows some initial concepts and some categories. 
Table 1. Analysis of open coding (part of examples).

\begin{tabular}{|c|c|c|}
\hline Statement Text & Conceptualization & Categorization \\
\hline $\begin{array}{l}\text { A02: We attend too many training sessions a year and } \\
\text { often go out to study. } \\
\text { A10: When I was studying abroad, I went to an } \\
\text { internship company. } \\
\text { A14: I have been studying once a month to engage in } \\
\text { advanced studies }\end{array}$ & $\begin{array}{l}\text { Regular training and study, } \\
\text { Self-regulated learning ability, } \\
\text { Regular study in famous schools }\end{array}$ & Learning ability \\
\hline
\end{tabular}

A06: I have a double degree in economic management and business administration.

A10: High school and university in UK, then after graduation, go to the United States for half a year. A13: My own education experience. I have a bachelor's

Overseas Study Experience, Double Degrees

Overseas Study Experience

Bachelor degree degree to tell the truth.

A02: We'll still assess the risk in advance, if it's too big, we can't do it without doing it.

A06 good industry I will only invest part of it, will not fully invest in it.

A14: I'm sure I'm going to report the uncertainties. I

think it's important for me to take risks into account. I'm not going to do anything risky.

A06: If I exceed this ability, I may go to a partnership.

A13: It's still a big risk, but if you can't get your foot out, you'll never get in.

A14: If I think the risks outweigh the benefits, I will

definitely refuse.

A02: I'm going to try.

A12: When you make a business, you have to be honest.

education

Risk assessment, conservative

Risk aversion

Risk preference

High risk tolerance

Relatively high-risk tolerance

Risk tolerance

Low risk tolerance

Complete risk aversion

Dare to try the unknown

Sincerity

Persistence
A13: Mind. I've been very persistent, and I have to

Personality traits the right road.

A10: I think innovation is more about reform, doing on the old, it's just a way of thinking.

A02: We are trying to inspire children's creativities and

entrepreneurial abilities.

A03: This spirit is constantly being discovered.

A01: I'm a state licensed intellectual property agent.

A07: It's assembly, and then the core technology is

distributed to you for patents.

A05: Is it a one-time purchase or does the government

keep charging you through information.

A02: For example, if there is a person who is in good

contact with the outside world but not good at business,

I will send someone to cooperate with him.

A07: The average age in the Chamber of Commerce is about 30 years old. The common feature of all of us is that we are full of momentum.

A06: We have some outsourced, fixed contract experts and teachers.

A10: I am more infected with the team, there is a better cohesion of this higher corporate culture, values.

A02: Because I think employees and talents are the core.

They must lead by themselves.

A08: Team learning awareness affects innovation and the

Keep curiosity, unique way of thinking

Cultivating Innovation Awareness

Innovation

Discover new things constantly

consciousness

State Licensed Intellectual Property Agent

Core Technology Patents

Annual government subsidy

Technology resources

biggest factor is that you keep learning.

A14: Other cities will be better at innovation policies. We have heard less about them here.

A11: Society may have an atmosphere for innovation and entrepreneurship.

A08: As long as you have such a capability, there are many platforms.
Bring Employee's Skills into Full Play

Team members' enthusiasm

Talent resources 
Table 1. Cont.

\begin{tabular}{|c|c|c|}
\hline Statement Text & Conceptualization & Categorization \\
\hline $\begin{array}{l}\text { A04: This is in the early stages, which are closely related } \\
\text { to the study of this policy. } \\
\text { A01: Relatively speaking, the present policy is macro and } \\
\text { the policy should be formulated according to the local } \\
\text { characteristics. } \\
\text { A11: The change of policy is too impacting. It may have } \\
\text { a fatal impact on an industry. }\end{array}$ & $\begin{array}{l}\text { Policy-oriented role } \\
\text { Specific environment, specific policy } \\
\text { Maintaining policy sensitivity }\end{array}$ & $\begin{array}{l}\text { Policy } \\
\text { orientation }\end{array}$ \\
\hline $\begin{array}{l}\text { A05: Actually, there are many people in difficulty. Now I } \\
\text { prefer to do some public welfare. } \\
\text { A03: As long as our company is not losing money, I } \\
\text { would like to do this thing, and it will probably end up } \\
\text { like a public welfare industry. } \\
\text { A04: When I was investing and doing business in new } \\
\text { energies, I made some low-carbon contributions to } \\
\text { Zhenjiang. }\end{array}$ & $\begin{array}{l}\text { Do Public Welfare and Return to Society } \\
\text { Providing employment opportunities } \\
\text { Solving Social Climate Problems }\end{array}$ & $\begin{array}{l}\text { Corporate social } \\
\text { responsibility } \\
\text { behaviors }\end{array}$ \\
\hline $\begin{array}{l}\text { A04: Let's say how many electric cars are required in the } \\
\text { province. The society needs some help from our } \\
\text { company. } \\
\text { A05: We help the government solve their problems. } \\
\text { Because the government also wants to make } \\
\text { achievements, we help them. } \\
\text { A06: It's okay cooperate with the government cautiously. }\end{array}$ & $\begin{array}{l}\text { Close cooperation between government and } \\
\text { enterprises } \\
\text { Synergetic development Keep Boundaries }\end{array}$ & $\begin{array}{l}\text { The relationship } \\
\text { between corporates } \\
\text { and government }\end{array}$ \\
\hline $\begin{array}{l}\text { A04: Now we are cooperating with Shanghai Electric } \\
\text { Power College. We are doing R\&D cooperation, and will } \\
\text { be on the market soon. } \\
\text { A03: We hope that through the entrance of the school, we } \\
\text { can get through the employment of students as they } \\
\text { graduate. } \\
\text { A07: We put some equipment in schools so teachers can } \\
\text { lead students research on it. }\end{array}$ & $\begin{array}{l}\text { Cooperating with Universities in R\&D } \\
\text { Innovation } \\
\text { Enterprises Train Reserve Talents from } \\
\text { Schools } \\
\text { Resource Sharing in Enterprises and } \\
\text { Universities }\end{array}$ & $\begin{array}{l}\text { The relationship } \\
\text { between corporates } \\
\text { and universities }\end{array}$ \\
\hline
\end{tabular}

\subsubsection{Axial Coding}

Through the analysis of all free nodes obtained in open coding, it was found that (Figure 2), according to the number of reference points in all nodes, the nodes with more reference points were determined as follows: personality traits, innovation consciousness, risk tolerance, risk preference, continuous learning, management ability, education, learning ability, talent resources, technology resources, corporate social responsibility behaviors, the relationship between enterprises and government, the relationship between enterprises and universities, the relationship between enterprises, the innovation environment, corporate culture and policy orientation. The 17 nodes with more reference nodes have certain influence on the innovation behaviors of the new generation entrepreneurs. Then, the 17 nodes were set up with simple logical relationships. Finally, the four nodes, entrepreneur innovation spirit, entrepreneur innovation ability, social capital and institutional environment, were listed as tree nodes.

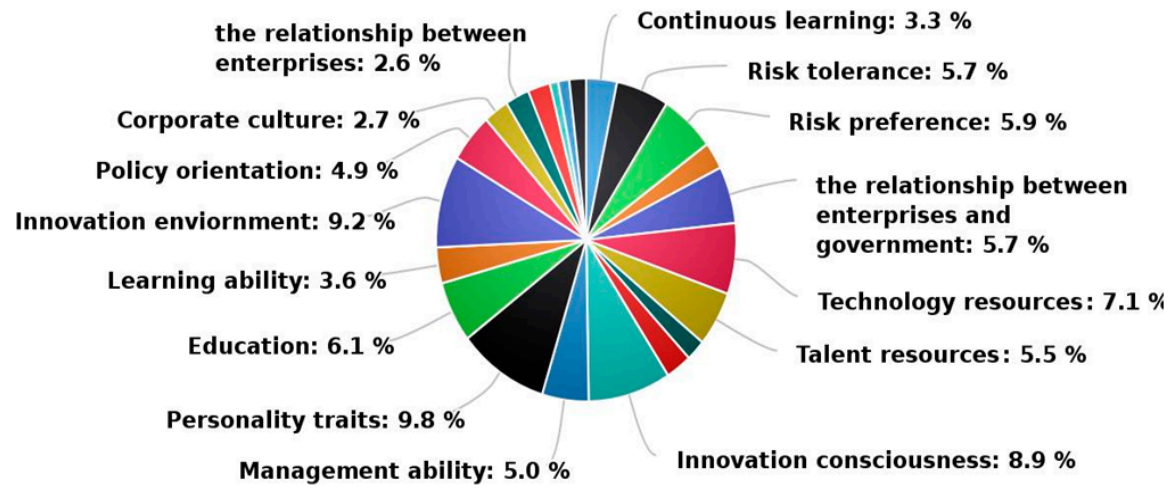

Figure 2. Proportion of reference points for free nodes. 
There are intrinsic relationships among different categories in open coding at the conceptual level. According to the relationship and logical order among 38 categories, this study concludes there are six main categories: entrepreneur innovation ability, entrepreneur innovation spirit, social capital, institutional environment, entrepreneur innovation behaviors and organization innovation performance. The specific implication is shown in Table 2.

Table 2. Examples of axial coding.

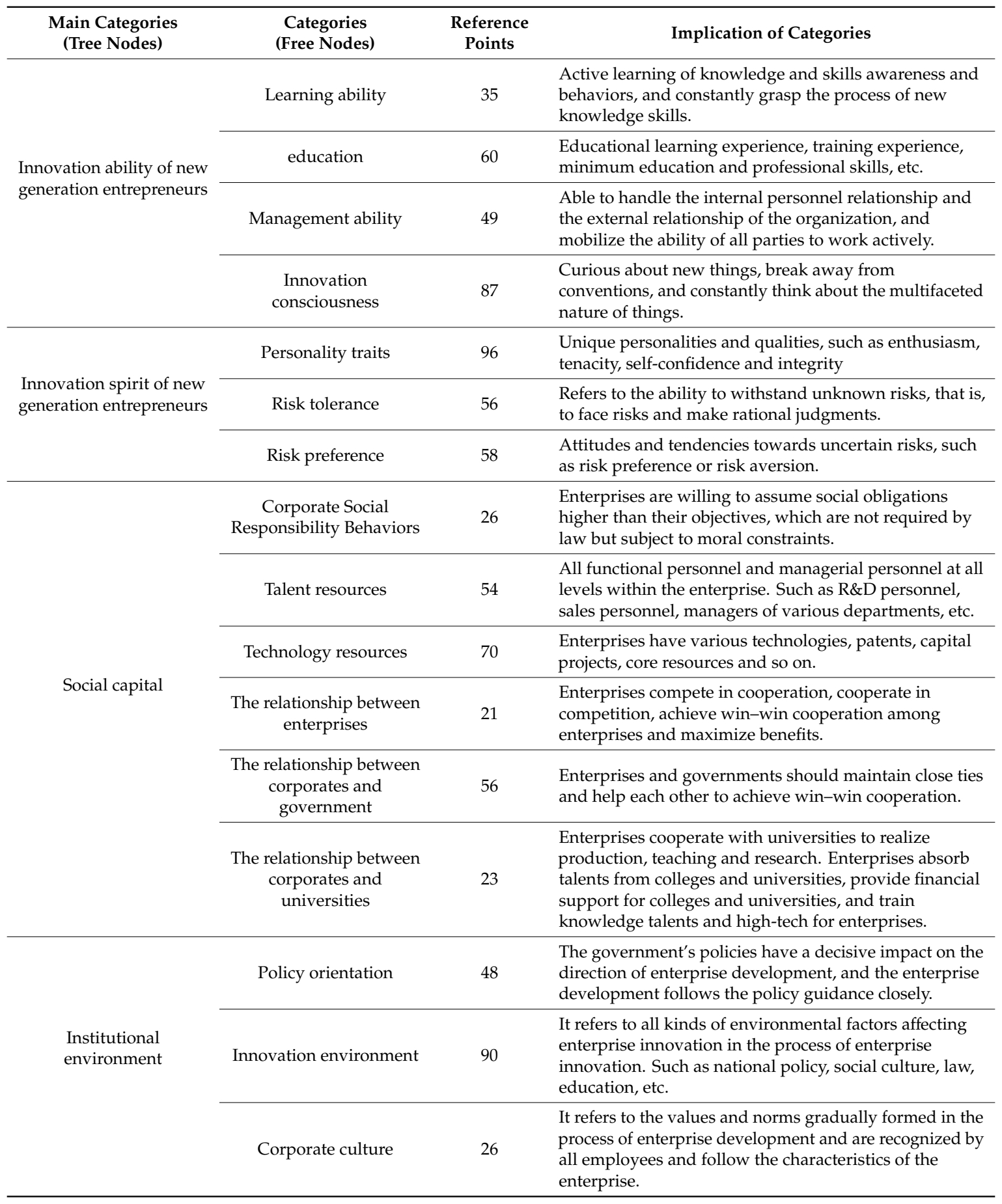


Table 2. Cont.

\begin{tabular}{cccl}
\hline $\begin{array}{c}\text { Main Categories } \\
\text { (Tree Nodes) }\end{array}$ & $\begin{array}{c}\text { Categories } \\
\text { (Free Nodes) }\end{array}$ & $\begin{array}{c}\text { Reference } \\
\text { Points }\end{array}$ & Implication of Categories \\
\hline $\begin{array}{c}\text { Innovation behaviors of } \\
\text { new generation } \\
\text { entrepreneurs }\end{array}$ & $\begin{array}{c}\text { Innovation in } \\
\text { management system }\end{array}$ & 24 & $\begin{array}{l}\text { Improve and develop the traditional management } \\
\text { system to make it more suitable for the current } \\
\text { development model of enterprises. }\end{array}$ \\
\cline { 2 - 4 } & $\begin{array}{c}\text { Innovation in Production } \\
\text { and Operation }\end{array}$ & 38 & $\begin{array}{l}\text { Improve and update the traditional way of enterprise } \\
\text { survival and operation. }\end{array}$ \\
\cline { 2 - 4 } & Financial performance & 13 & $\begin{array}{l}\text { Quantitative evaluation of an enterprise's profitability in } \\
\text { a certain period of time. }\end{array}$ \\
\hline $\begin{array}{c}\text { Organization } \\
\text { performance }\end{array}$ & Growth performance & 10 & $\begin{array}{l}\text { It refers to the increase of enterprise assets, the } \\
\text { expansion of market and the expansion of personnel } \\
\text { scale and the innovation of the nature, structure and } \\
\text { main body of enterprise business. }\end{array}$ \\
\hline
\end{tabular}

\subsubsection{Selective Coding and Theoretical Model}

Selective coding is a process of constructing theoretical models by extracting core categories from main categories and other categories and analyzing the correlation paths between core categories and other categories. Through the original interview materials, the formed categories and summarized six main categories, namely entrepreneur innovation ability, entrepreneur innovation spirit, social capital, institutional environment, entrepreneur innovation behavior, organizational innovation performance, the typical relational structure of the main category is shown in Table 3. In addition, a continuous comparative study and in-depth analysis of these six main categories was performed, which regarded "the influencing factors of the innovative behavior of the new generation entrepreneurs" as the core category. The two categories of "innovative ability of new generation entrepreneurs" and "innovative spirit of new generation entrepreneurs" originate from entrepreneurs themselves, which can be regarded as internal factors affecting innovative behavior. To adapt to the changing environment, entrepreneurs' innovative ability and innovative spirit drive entrepreneurs to innovate bravely. In addition, the two categories of "social capital" and "institutional environment" are uncertain factors beyond the control of the new generation entrepreneurs themselves. Social capital and the institutional environment directly affect the innovative behavior of the new generation entrepreneurs. On this basis, this study further explored the logical relationship between innovation behavior and innovation performance of the new generation entrepreneurs, and ultimately refined the core category of "factors affecting entrepreneurs' innovation behavior and further role in organizational innovation performance". The "story line" around the core category can be summarized as: the impact of entrepreneur innovation behavior, innovation spirit, social capital and enactment environment on entrepreneur innovation behavior, as well as the further role of organizational innovation performance. Based on this "story line", this study constructed the influencing factors of innovative behavior of new generation entrepreneurs and the model of organizational innovation performance, as shown in Figure 3. 
Table 3. Categories of typical relational structure.

\begin{tabular}{lll}
\hline \multicolumn{1}{c}{ Typical Relational Structure } & Connotation of Relational Structure & \multicolumn{1}{c}{ Statement Text (Part of Examples) } \\
\hline $\begin{array}{l}\text { Entrepreneur's Innovation Ability } \rightarrow \\
\text { Entrepreneur's Innovation behaviors }\end{array}$ & $\begin{array}{l}\text { The entrepreneur's learning ability and } \\
\text { education level have a remarkable } \\
\text { impact on the entrepreneur's innovation } \\
\text { behaviors. }\end{array}$ & $\begin{array}{l}\text { The so-called driving force comes from } \\
\text { continuous learning. External factors } \\
\text { may only serve as a reference and other } \\
\text { successful experiences of enterprises } \\
\text { may be learned. }\end{array}$ \\
\hline & The entrepreneurs' personal
\end{tabular}

Entrepreneur's Innovation Spirit $\rightarrow$ Entrepreneur's Innovation Behaviors characteristics, risk preference and innovation consciousness have remarkable effects on entrepreneurs' innovation behaviors.

Social Capital $\rightarrow$ Entrepreneur's Innovation Behaviors
Internal and external social capital have a remarkable impact on entrepreneurs' innovation behaviors.
Constantly desire to discover.

It was because there was no shortage of money in the market at that time, and then the banks and the government had more money on their side. Now we can only share a few times in the form of contract alliance, just a dozen enterprises, and will cooperate together.

That is to say, the market is not short of money, and the government's various subsidies are relatively hot. Now we may innovate by organizing, organizing relevant activities by government agencies, etc.

Because as long as you innovate, you will always have money. Don't worry about not having money. If you want to achieve success, you must innovate. If you dare to innovate, I dare to match.
Entrepreneur's Innovation Behaviors $\rightarrow$ Organization performance
Different innovation behaviors of entrepreneurs have a remarkable impact on the financial performance and growth performance of the organization.
Policy orientation, innovation remarkable effects on entrepreneurs

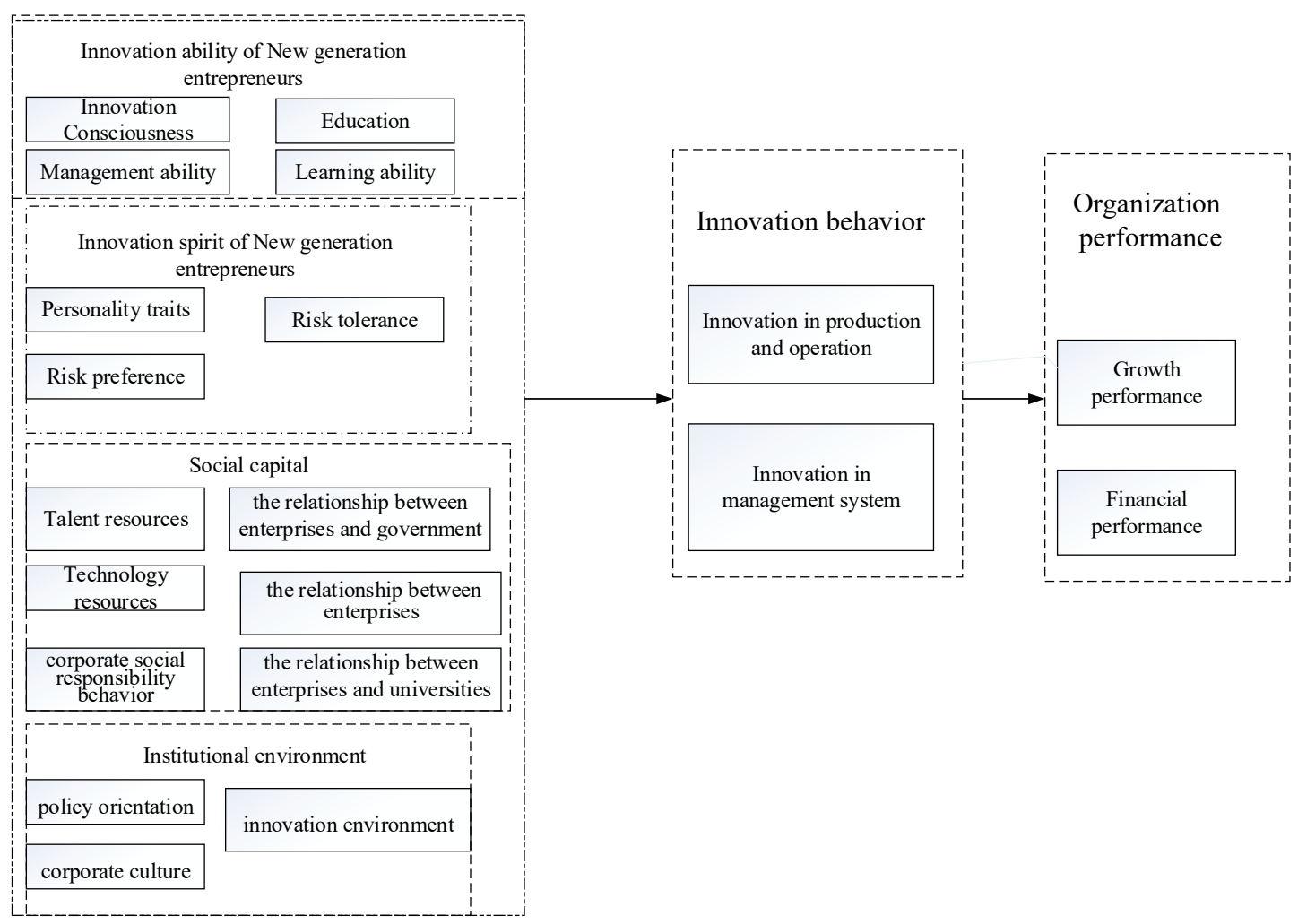

Figure 3. Model of influential factors of the innovation behaviors of new generation entrepreneurs and organization performance. 


\subsubsection{Theoretical Saturation}

When the newly collected data fail to present new concepts or categories, i.e., theoretical saturation, the collection of data can be stopped. To test the saturation of the conceptual model, the grounded coding theory of the same process was analyzed and saturation test was carried out on eight randomly selected interview records and 16 textual materials. No new categories and relationships were found. Thus, sampling could be stopped. The results show that the theoretical model was saturated and complete [46].

\section{Research Analysis and Results}

\subsection{Factors Influencing Innovation Behaviors of New Generation Entrepreneurs}

With grounded theory, we used NVivo11 to code information in three levels. Each coding nodes relationships showed a subordinate structure. The first-level nodes analyzed all raw materials and included generalized abstraction of entrepreneurs' behaviors.

\subsubsection{Macro-factors}

The results of qualitative research software NVivo 11 show that social capital, entrepreneur innovation spirit, entrepreneur innovation ability and institutional environment are the macro-factors affecting the innovation behaviors of the new generation entrepreneurs, i.e. the first-level nodes of document coding. The percentage of reference points of each node is shown in Figure 4. The number of reference points indicates the effect degree of the given factor.

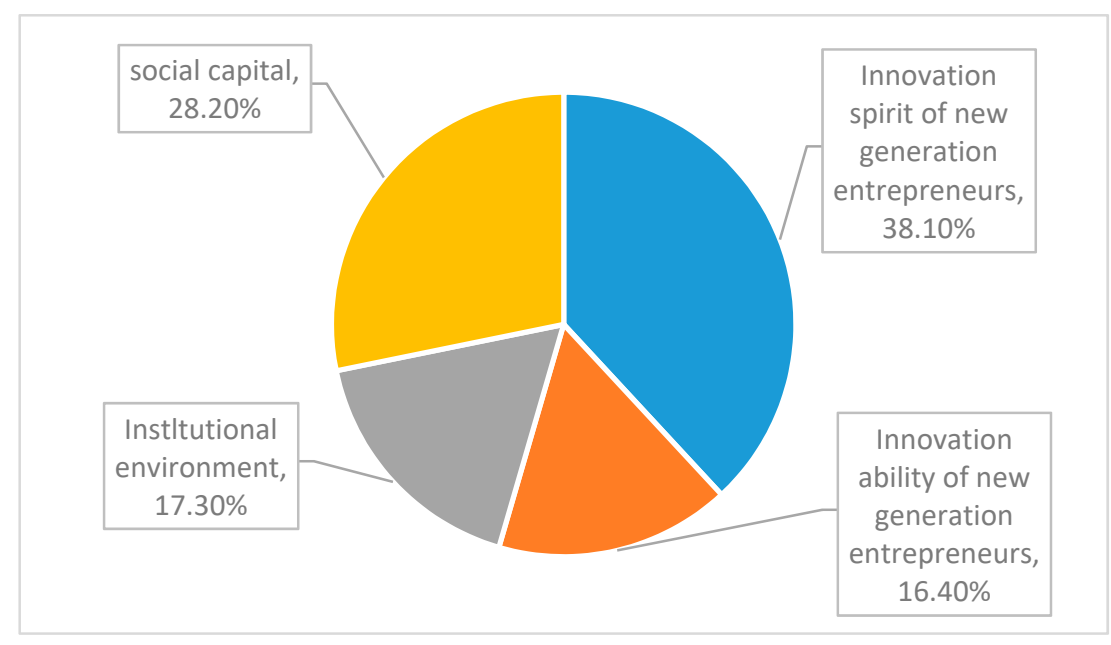

Figure 4. Percentage of first-level nodes at reference points.

From the percentage of first-level nodes at coding reference points in Figure 4, we can see that, among the macro-factors affecting the innovation behaviors of the new generation entrepreneurs, social capital and entrepreneurship have more reference points in the original data and they sum to more than half of all the codes. However, the number of reference points in the institutional environment and entrepreneur's innovation ability are relatively few and very close. This phenomenon shows the impact of institutional environment and entrepreneur's innovation ability is somehow not high or needs further research [47].

\subsubsection{Micro-factors}

The subordinate structure formed by the three-level coding in grounded theory makes the reference points of the first-level node depend on the sum of all reference points in its subordinate nodes and its own nodes. Exploring the factors affecting entrepreneurs' innovation behaviors should 
not only stay at the macro level, but also analyze the micro-factors contained in each macro-factor in detail, which is more helpful for a clear understanding of the innovation mechanism of the new generation entrepreneurs.

(1) Social Capital

Corporate social capital is a logical starting point for an enterprise to gain competitive advantage and grow continuously [48]. Firstly, in the interview data, it was found that enterprises realize the protection of technology patents by acquiring independent intellectual property rights, and attach great importance to the source of funds (such as government loans, subsidies and financing), which shows that the scientific and technological resources and funds owned by enterprises are the support of enterprise innovation. At the same time, through the coding of the data, it was found that the of technological capital has the most reference point (see Table 4), which also shows that the grasp of intangible technological resources and the flow of capital are the main supports of entrepreneurs' innovative behavior. Secondly, corporate social responsibility behavior is an important factor that cannot be ignored in the development of enterprise innovation [49]. Through qualitative research, it was found that many enterprises who are keen on social responsibility deem that the development of enterprises benefits from society, thus it is necessary for enterprises to do some public welfare to repay society, such as providing employment opportunities, green development and environmental protection. Finally, through the analysis of interview data, it was found that enterprises always pay close attention to any policy trends of the government and maintain close cooperation with the government. Moreover, enterprises can achieve the goal of resource sharing and cooperative innovation by establishing enterprise alliances. Enterprises have good relations with the government, other enterprises and universities, which enable enterprises to obtain resources conducive to their own innovation and development, such as policy information, industry technology resources, and innovative talents.

Table 4. Reference points for social capital coding.

\begin{tabular}{llll}
\hline First-Level Nodes & Second-Level Nodes & Material Sources & Reference Points \\
\hline & Technology resources & 10 & 70 \\
& Talent resources & 13 & 54 \\
Social capital & the relationship between enterprises and government & 11 & 56 \\
& the relationship between enterprises & 6 & 21 \\
& the relationship between enterprises and universities & 7 & 23 \\
& corporate social responsibility behaviors & 11 & 26 \\
\hline
\end{tabular}

(2) Innovation Spirit of Entrepreneurs

Entrepreneurship is the fundamental force for the innovation and development of an enterprise [50]. In today's unpredictable environment, subverting the ubiquitous Internet era, enterprises need a spiritual leader to lead the innovation of enterprises. Peter Drucker believed that the essence of entrepreneurship is change, which includes innovation, adventure and trust. Through qualitative research, it was found that entrepreneurs with high innovative spirit possess such characteristics as bravery, self-confidence, persistence, risk preference for trying new things, and tolerance for unknown things. In addition, the encoding of interview data show that entrepreneurs' personality traits have the most reference points (see Table 5). It shows that entrepreneurs' innovative spirit is to a large extent some of their innate personal qualities, such as perseverance, never giving up, self-confidence, imagination and so on. On the one hand, a self-confident and persistent entrepreneur will not give up easily, and pay attention to market demand and technological innovation of enterprises; and unremittingly explore how to create new products, new models and new ideas. On the other hand, an entrepreneur with high risk preference and risk tolerance is often more able to bear the risk of transformation, facing the uncertainty of transformation, and looking forward to the long term [51]. Therefore, entrepreneurship plays a vital role in the innovation and development of enterprises. 
Table 5. Reference points for enterprisers' innovation spirit coding.

\begin{tabular}{cccc}
\hline First-Level Nodes & Second-Level Nodes & Material Sources & Reference Points \\
\hline \multirow{2}{*}{ Innovation spirit of } & Personality traits & 14 & 96 \\
entrepreneurs & Risk preference & 12 & 58 \\
& Risk tolerance & 13 & 56 \\
\hline
\end{tabular}

\section{(3) Institutional Environment}

In this study, institutional environment includes innovation environment, policy orientation and corporate culture. The external institutional environment (policy orientation) and internal institutional environment (corporate culture) of an enterprise have an important impact on the generation and operation of the enterprise. On the one hand, the entrepreneurs interviewed generally expressed that major policy changes would have a fatal impact on enterprises. Therefore, they should always pay attention to the government's policies and change the innovation activities of enterprises in time to match the government's policies, which is consistent with the research of Uyarra et al.(2016) [52], that is, whether an enterprise chooses innovation depends on the matching of innovation policies and activities. On the other hand, in most of the enterprises interviewed, we found that these enterprises have a common feature: high cohesion, good innovation atmosphere and strong learning atmosphere within the organization. Enterprises provide employees with an open and free working environment, and encourage employees to boldly try and continue to learn; this corporate culture is very conducive to the innovation and development of enterprises [53].

\section{(4) Entrepreneur's Innovation Ability}

Entrepreneur's innovative ability refers to the potential ability of entrepreneurs to create new methods and theories based on their original knowledge and experience and their own skills in the process of innovation, so as to adapt to the changeable environment [54]. According to interviews, entrepreneurs with broad vision and quick thinking tend to have a higher sense of innovation. They constantly explore new things and find new problems, which shows that innovation consciousness largely determines innovation ability. The whole innovation is an activity to achieve new goals under the control of innovation consciousness [55]. Secondly, the majority of entrepreneurs interviewed have received higher education, and continue to study abroad after graduation from universities to maintain their competitiveness. Finally, managerial ability and learning ability are also the key factors affecting entrepreneurs' innovative behavior. Good organizational management ability, personnel management ability and operation management ability are the important guarantees for entrepreneurs to innovate smoothly [56]. Through the analysis of interview data, it was found that entrepreneurs have strong learning ability, and constantly learn the industry knowledge and related industry knowledge, learn from competitors, and continue to innovate.

\subsection{The Impact of Innovation Behaviors on New Generation Entrepreneurs on Organization Performance}

Through the queries function of Nvivo11 software, the concepts of "entrepreneur innovation behaviors" and "organization performance" were sorted as the query conditions for rows and columns of the matrix. The results of matrix coding are shown in Table 6. Through comparison, it was found that the main factors affecting organization performance are innovation in management system and innovation in production. (1) Management system innovation has a significant impact on organizational growth performance [57]. In the interview records, it was found that in the process of optimizing management mode and innovating management system, enterprises can find and solve potential problems in the management process in time, such as human resources management system, performance management system, etc., to ensure the smooth development and growth of enterprises. (2) Production and operation innovation mainly affect the financial performance of the organization. Production and operation refer to the activities related to the conversion of production materials into 
products. By means of technological innovation and introducing advanced equipment, enterprises can maximize profits and ultimately improve their financial performance [58].

Table 6. Proportion of reference points for matrix coding.

\begin{tabular}{lccc}
\hline & Organization Performance & Financial Performance & Growth Performance \\
\hline entrepreneur innovation behaviors & 58 & 48 & 56 \\
Innovation in management system & 42 & 29 & 37 \\
Innovation in production & 56 & 42 & 49 \\
\hline
\end{tabular}

\section{Conclusion and Prospect}

\subsection{Conclusions}

This study used grounded research methods through qualitative analysis with NVivo11 to create free nodes, tree nodes and relationship nodes for 16 young entrepreneurs' interviews and generated a logical model, which enriches and supplements the theory of entrepreneurs' innovation behaviors and can provide theoretical support for the new generation entrepreneurs' innovation behaviors. The model is to show the influence of innovation behaviors on new generation entrepreneurs and organization performance. The model includes four dimensions that affect the innovation behaviors of the new generation entrepreneurs: the innovation ability of the new generation entrepreneurs, the innovation spirit of the new generation entrepreneurs, social capital and institutional environment. Each dimension contains specific factors as well as two key elements of the innovation behaviors and organizational performance of the new generation entrepreneurs. The main conclusions of this study are as follows: (1) Based on the grounded theory, this study explored the constituent factors of social capital: technical capital, human resources, corporate social responsibility behavior, enterprise-government relationship, enterprise-university relationship and enterprise-enterprise relationship. It was found that these factors have far-reaching impact on enterprise innovation behavior. This finding is consistent with Dyer and Singh's (1998) study. Dyer and Singh believed that enterprises can maintain long-term cooperation through establishing good relations with enterprises, so that enterprises have more resources for innovation and enhance their investment in innovation resources [59]. Moreover, the findings are similar to Amiraslani et al.'s (2017) research on corporate social responsibility behavior. Scholars believe that enterprises mainly influence their innovation behavior through social responsibility behavior [60]. However, this study found that different factors have different effects on innovation behavior under social capital, that is, factors with more reference points have greater impacts on innovation behavior. (2) This study found that the innovative spirit of the new generation entrepreneurs is the main influencing factor of innovative behavior through macro-analysis. Further, from the micro analysis, it was found that personality traits in the category of entrepreneur's innovation spirit have the greatest impact on entrepreneurs' innovation behaviors. (3) This study used NVivo to explore the logical relationship between entrepreneur innovation behavior and organizational innovation performance, and found that the main factors affecting organizational innovation performance are innovation in management system and innovation in production. This finding is consistent with Rasheed and Muhammad Athar's research on management system innovation. That is to say, the innovation of entrepreneurs' personnel management system, salary system and performance evaluation system effectively improves the growth performance of enterprises [61]. However, this the impact of innovation behavior on organizational performance from a micro perspective was further studied, and we found that management system innovation has a significant impact on organizational growth performance, and production and operation innovation mainly affect organizational financial performance.

\subsection{Policy Implications}

Through this study, the following two policy implications are put forward on how to promote the innovative behavior of the new generation entrepreneurs: (1) Entrepreneurship should be cultivated 
by strengthening entrepreneurship education and training. The entrepreneurship culture in a region can also influence the development of entrepreneurship and the degree of innovation. Through entrepreneur education and training, we can accelerate the formation of entrepreneurship culture, enhance entrepreneurs' ability to identify opportunities and bear risks, and improve their innovation enthusiasm. The state should pay attention to entrepreneurship education and entrepreneurship skills training, and promote the formation of more innovative spirit through the spillover of knowledge and culture. (2) Entrepreneurs' innovative vitality should be stimulated by creating a good institutional environment. To create a good environment for entrepreneurs to innovate, we give two suggestions: On the one hand, we should establish and improve the intellectual property protection system. We should strengthen the legal guarantee of innovation, formulate and timely amend relevant local laws and regulations on scientific and technological innovation, make relevant rules and policies fully open, and promote market players to make full use of innovation policies. On the other hand, we should create an innovative social atmosphere, establish and improve the fault-tolerant and error-correcting mechanism, and make no negative evaluation of the units and individuals who are diligent and responsible in innovative activities but fail to achieve the expected goals, so they do not affect the performance appraisal and promotion of use, so as to create a social atmosphere that encourages innovation.

\subsection{Research Limitation and Prospect}

The shortcomings of this study are that, due to the limitations of research conditions, only new generation entrepreneurs in Jiangsu area were studied and thus comparison for regional differences was not performed. Innovative behavior has distinct regional, cultural and historical characteristics. In future research, we will expand the collection of samples to get more general results for the innovative behavior of new generation entrepreneurs. Meanwhile, the theoretical model constructed in this study can provide reference for future researchers to conduct quantitative research on the innovation of new generation entrepreneurs.

Author Contributions: Writing_original draft and Data curation, Z.Z., J.J.; Data curation, J.J.; Supervision and Validation, H.G., S.G. and A.Z.; and Writing-review and editing, A.Z.

Funding: This work was supported by the National Natural Science Foundation of China under Grant 71704066.

Acknowledgments: The authors are indebted to the anonymous reviewers for their very insightful comments and constructive suggestions, which helped improve the quality of this paper.

Conflicts of Interest: The authors declare no conflict of interest.

\section{References}

1. Homburg, C.; Stierl, M.; Borne Mann, T. Corporate social responsibility in business-to-business markets: How organizational customers account for supplier corporate social responsibility engagement. J. Mark. 2013, 7, 54-72. [CrossRef]

2. Vallejo Martos, M.C. What is a family business? A discussion of an integrative and operational definition. Int. J. Entrep. Small Bus. 2007, 4, 473-488.

3. Han, J.Y. Research on the team construction of new generation private entrepreneurs. Enterp. Reform Manag. 2014, 11, 76-77.

4. Salgado Banda, H. Entrepreneurship and economic growth An empirical analysis. J. Dev. Entrep. 2007, 12, 3-29. [CrossRef]

5. Chen, S.; Chen, F. The path choice of cultivating the new generation private entrepreneurs. Lilun Daobao 2013, 12, 31-32.

6. Wang, X.X.; Wang, C.H.; Che, C.C. The impacts on both family and personal factors for youth entrepreneurship. J. Discret. Math. Sci. Cryptogr. 2018, 21, 1205-1209. [CrossRef]

7. Vondracek, F.W. Occupational dreams, choices and aspirations: Adolescents' entrepreneurial prospects and orientations. J. Adolesc. 2002, 25, 65-78. 
8. Sukrug Mehmet, M.; Mehmet, S. Characteristics and attitudes of entrepreneurs towards entrepreneurship. Proc. Soc. Behav. Sci. 2015, 195, 1087-1096.

9. Zainol, F.A.; Ayadurai, S. Entrepreneurial orientation and firm performance: The role of personality traits in Malay family firms in Malaysia. Int. J. Bus. Soc. Sci. 2011, 2, 59-71.

10. Fan, X.G.; Lu, P. The social composition of China's private entrepreneurs: Class and cohort differences. Soc. Sci. China 2019, 40, 42-62.

11. Chen, J.P. The role orientation and quality construction of the new generation of entrepreneurs. Leg. Syst. Soc. 2007, 12, 630-670.

12. Jiang, X.J.; Cao, W. Research on the value orientation and political guidance of the new generation of entrepreneurs: An empirical investigation based on Zhejiang province. J. Cent. Inst. Soc. 2016, 1, 77-82.

13. Wang, H.J. Study on high-level management talent cultivation mechanism driven by innovation. Value Eng. 2018, 37, 44-46.

14. Zhang, B.; Wei, T.T. On intergenerational transmission and feedback of new Zhejiang merchants. J. Zhejiang Youth Coll. 2013, 31, 15-18.

15. Lorrain, J.; Raymond, L. Young and older entrepreneurs: An empirical study of difference. J. Small Bus. Entrep. 1991, 8, 51-61. [CrossRef]

16. Pang, F. Research on the cultivation of college students' entrepreneurial competence based on the perspective of the growth of new generation entrepreneurs. Enterp. Econ. 2014, 6, 68-72.

17. Johnson, D. What is innovation and entrepreneurship Lessons for larger organizations. Ind. Commer. Train. 2001, 33, 135-140. [CrossRef]

18. Li, H.B.; Li, X.Y.; Zhang, H.F.; Zhang, J.S. Examining the impact of business entrepreneurship and innovation entrepreneurship on economic growth in China. Econ. Res. J. 2009, 44, 99-108.

19. Zhang, W. China's future growth depends on innovation entrepreneurs. J. Chin. Econ. Bus. Stud. 2017, 15, 19-40. [CrossRef]

20. Jones, T.; Ram, M.; Villares-Varela, M. Diversity, economic development and new migrant entrepreneurs. Urban Stud. 2019, 56, 960-976. [CrossRef]

21. Yuan, Y.Z. The hitch to China's enterprisers' creative behaviour. Manag. World 2002, 5, 143-144.

22. Zhou, J.Z. Enterprise innovation behaviour model and its internal mechanism analysis. Commer. Times 2017, 18, 99-102.

23. Yuan, Y.Z. Barriers to innovation behaviours of Chinese entrepreneurs. Manag. World 2002, 5, 143-144.

24. Wang, G.Z. The present situation and guidance of the growth of the new generation private entrepreneurs. J. Liaoning Inst. Soc. 2018, 2, 82-86.

25. He, L.L.; Zhu, F.M.; Chen, H.W. Analysis of obstacles of Innovation Behaviours among Private Entrepreneurs. Sci. Technol. Manag. Res. 2009, 29, 406-408.

26. Luan, M.T.; Fang, X.; AO, Y.C. Analysis on the dilemma and breakthrough of new generation entrepreneurs' entrepreneurship. Caizhi 2018, 5, 219-220.

27. Gui, T.W.; Du, J.G.; Jiang, Q.Q. Research on the Influencing Factors of the Entrepreneur's Innovation Will. Sci. Technol. Manag. Res. 2018, 38, 24-29.

28. Conner, M.; Armitage, C.J. Extending the theory of planned behaviour: A review and avenues for further research. J. Appl. Soc. Psychol. 1998, 28, 1429-1464. [CrossRef]

29. Lal, A.K.; Clement, R.W. The role of individual enterprise and entrepreneurial spirit. Asia-Pac. Dev. J. 2005, 12, 81-99. [CrossRef]

30. Aldieri, L.; Vinci, C.P. Green economy and sustainable development: The economic impact of innovation on employment. Sustainability 2018, 10, 3541. [CrossRef]

31. Piva, M.; Vivarelli, M. Is innovation destroying jobs? Firm-level evidence from the EU. Sustainability 2018, 10, 1279. [CrossRef]

32. Kanter, R.M. Structural, collective and social conditions for innovation in organization. Res. Organ. Behav. 1988, 10, 169-211.

33. Waheed, A.; Miao, X.M. How New HRM practices, organizational innovation and innovative climate affect the innovation performance in the IT industry: A moderated-mediation analysis. Sustainability 2019, 11, 621. [CrossRef]

34. Hartmann, A. The role of organization culture in motivating innovation behaviour in construction firms. Constr. Innov. 2006, 6, 159-172. [CrossRef] 
35. Shanker, R.; Bhanugopan, R.; Van der Heijden, B.I.; Farrell, M. Organizational climate for innovation and organizational performance: The mediating effect of innovative work behaviour. J. Vocat. Behav. 2017, 100, 67-77. [CrossRef]

36. Liu, X.F.; Xie, Y.Y. Exploratory innovation, exploitative innovation and firm performance: Moderating effect of organizational structure and slack resources. In Proceedings of the PICMET '14 Conference: Portland International Center for Management of Engineering and Technology; Infrastructure and Service Integration, Kanazawa, Japan, 27-31 July 2014.

37. Chistensen, J.F. Asset profiles for technological innovation. Res. Policy 1995, 24, 727-745. [CrossRef]

38. Prajogod, A.; Hamed, P.K. Relationship between innovation stimulus, innovation capacity, and innovation performance. RD Manag. 2006, 36, 499-515.

39. Xiao, W.Q.; Chen, H.L. On the innovation of enterprise management system. Mark. Mod. 2006, 11, 161-162.

40. Miotti, L.; Sachwald, F. Co-operative R\&D: Why and with whom? An integrated framework of analysis. Res. Policy 2003, 8, 1481-1499.

41. Hogan, S.J.; Coote, L.V. Organizational culture, innovation, and performance: A test of Schein's model. J. Bus. Res. 2014, 67, 1609-1621. [CrossRef]

42. Audretsch, D.B.; Coad, A.; Segarra, A. Firm growth and innovation. Small Bus. Econ. 2014, 43, 743-749. [CrossRef]

43. Glazer, B.; Anselm, S. The Discovery of Grounded Theory: Strategies for Qualitative Research; Aldine Publishing Company: Chicago, IL, USA, 1967.

44. An, Y.F. Qualitative data analysis software NVivo application analysis. China Sci. Technol. Inf. 2012, 5, 66-67.

45. Cascio, M.A.; Lee, E.; Vaudrin, N.; Freedman, D.A. A team-based approach to open coding: Considerations for creating intercoder consensus. Field Methods 2019, 31, 116-130. [CrossRef]

46. Strauss, A.; Corbin, J. Basics of qualitative research: Techniques and procedures for developing grounded theory, 2 nd ed.; Sage Publications: Thousand Oaks, CA, USA, 1998.

47. Huo, M.K.; Zha, J.J.; Zhu, J.Q. Research on the influencing factors of information acquisition behavior of students' innovation and entrepreneurship team based on grounded theory. Mod. Inf. 2019, 39, 46-51.

48. Barney, J.B. Resource-based theories of competitive advantage: A ten-year retrospective on the resource-Based view. J. Manag. 2001, 27, 643-650. [CrossRef]

49. Wang, X.D.; Feng, M.M.; Palmer, T.B. Interactive effects of corporate social responsibility and other value-creating investments on corporate financial performance. Int. J. Sustain. Strateg. Manag. 2016, 5, 127-148. [CrossRef]

50. McLuskie, P. Innovation and entrepreneurship. Int. J. Entrep. Behav. Res. 2017, 23, 159-160. [CrossRef]

51. Kraiczy, N.D.; Hack, A.; Kellermanns, F.W. What makes a family firm innovative? CEO risk-taking propensity and the organizational context of family firms. J. Prod. Innov. Manag. 2015, 32, 334-348. [CrossRef]

52. Uyarra, E.; Shapira, P.; Harding, A. Low carbon innovation and enterprise growth in the UK: Challenges of a place-blind policy mix. Technol. Forecast. Soc. Chang. 2016, 103, 264-272. [CrossRef]

53. Chang, Y.S.; Yu, K.C. The relationship between perceptions of an innovative environment and creative performance in an online synchronous environment. Comput. Hum. Behav. 2015, 49, 38-43. [CrossRef]

54. Pellegrino, G.; Piva, M.; Vivarelli, M. How do new entrepreneurs innovate? Econ. E Political Ind. 2015, 42, 323-341. [CrossRef]

55. Green, W.; Cluley, R. The field of radical innovation: Making sense of organizational cultures and radical innovation. Ind. Mark. Manag. 2014, 43, 1343-1350. [CrossRef]

56. Mahoney, P.; Hall, S. Use process knowledge management systems to accelerate innovation. Hydrocarb. Process. 2016, 95, 45-50.

57. Garechana, G.; Río-Belver, R.; Bildosola, I.; Salvador, M. Effects of innovation management system standardization on firms: Evidence from text mining annual reports. Sci. Metr. Int. J. All Quant. Asp. Sci. Sci. Policy 2017, 111, 1987-1999. [CrossRef]

58. Antoncic, B.; Prodan, I. Alliances, corporate technological entrepreneurship and firm performance: Testing a model on manufacturing firms. Technovation 2008, 28, 257-265. [CrossRef]

59. Dyer, J.H.; Singh, H. The Relational View: Cooperative strategy and sources of interorganizational competitive advantage. Acad. Manag. Rev. 1998, 23, 660-679. [CrossRef] 
60. Amiraslani, H.; Lins, K.V.; Servaes, H.; Tamayo, A. A Matter of Trust? The Bond Market Benefits of Corporate Social Capital during the Financial Crisis; Social Science Electronic Publishing: London, UK, 2017.

61. Rasheed, M.A.; Shahzad, K.; Conroy, C.; Nadeem, S.; Siddique, M.U. Exploring the role of employee voice between high-performance work system and organizational innovation in small and medium enterprises. J. Small Bus. Enterp. Dev. 2017, 24,670-688. [CrossRef]

(C) 2019 by the authors. Licensee MDPI, Basel, Switzerland. This article is an open access article distributed under the terms and conditions of the Creative Commons Attribution (CC BY) license (http://creativecommons.org/licenses/by/4.0/). 